\title{
Burning rate measurement of composite propellant using acoustic wave emission in comparison with other techniques
}

\author{
Original \\ Article \\ Eslam Elsaka, Sherif Elbasuney, Hosam E. Mostafa, Tarek M. Elhedery, A. M. \\ Eldakhakhny
}

Department of Chemical Engineering, Military Technical College

\section{Keywords:}

Burning under water, burning rate, caustic wave emission, Composite propellant.

\section{Corresponding Author:}

Eslam Elsaka, Department of Chemical Enigneering, Tel: $\quad 01063638357$,

Email: eng.elsaka12@gmail.com

\section{Abstract}

The burning rate of rocket propellants is one of the most important parameters having a direct influence on itsballistic characteristics, so accurate measurement of thisparameter is an active approach for achieving optimum design of the solid rocket motors. In this paper, acoustic emission technique was applied for measuring the burning rate of a composite propellant and tests were performed on a wide Pressure range $(5-9 \mathrm{MPa})$ at ambient temperature. $3 \%$ as a deviation co-efficient of acousticemission technique wasinvestigated by comparingthe burning rate results obtained by this technique and those obtained byactual burning of a small-scale test motors at $6.894 \mathrm{MPa}$ (1000 PSI) and curves obtained from previously mentioned techniques were analyzed.This paper reports that theacoustic emission technique is a simple, effective, economic, time-saving, reliable technique with a high accuracy nearly equivalent to the active field resultsand it is suitable for quality control of large-scale productions of composite propellant..

\section{INTRODUCTION}

The burning rate is a mainly characteristic parameter controlling the ballistic behavior of the solid rocket propellants and it is an operative factor for assessment the efficiency of the overall rocket motor design ${ }^{[1-3]}$. The burning rate of rocket propellants is subject to an exponential relation so it must be controlled throughout the burning period to avoid catastrophic rise in chamber pressure or abnormal, interrupted, unstable burning or chuffing phenomenon ${ }^{[4]}$. Common factors affecting the burning rate are the combustion chamber pressure, the initial temperature of the propellant grain, the composition of the propellant including mainly level and particle size of both oxidizers and burning rate modifiers ${ }^{[5-7]}$, grain geometry, erosive burning and motor vibration ${ }^{[8,9]}$.

Depending on phenomenon combined with propellant burning shown in Figure 1 many techniques have been introduced and developed till now shown in Table 1.

Smooth scaling-up from strand burner to sub-scale motorthen to full-scale onewith high accurate measurement of burning rate is the most critical challenge of rocket propellant industry\{Formatting Citation .

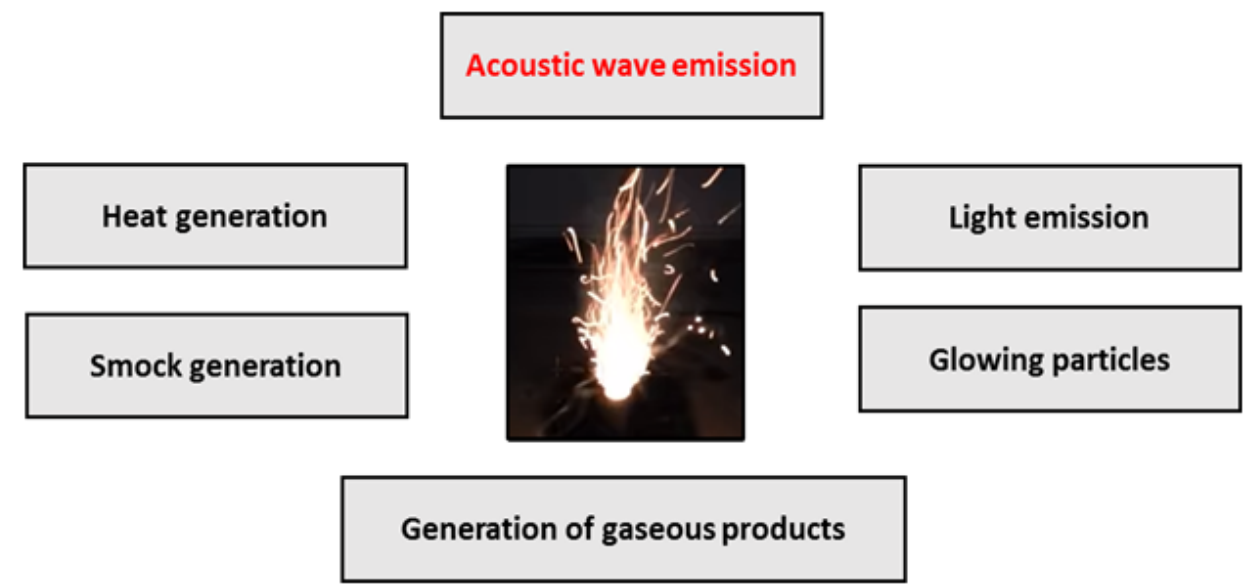

Fig. 1: Accompanying aspects to propellant burning process 
Table 1: Briefed survey on propellant burning rate measurement techniques.

\begin{tabular}{|c|c|c|c|c|}
\hline Year & Author & Technique & Principle & Ref \\
\hline 1974 & B.L. Crawford & $\begin{array}{l}\text { Strand burner with } \\
\text { Impeded wires }\end{array}$ & $\begin{array}{l}\text { Electrical measurement of time interval for end- } \\
\text { burning powder strand with predetermined length. }\end{array}$ & {$[11]$} \\
\hline 1998 & Desh. Deepak & $\begin{array}{l}\text { Ultrasonic pulse- } \\
\text { echo technique. }\end{array}$ & $\begin{array}{l}\text { Emitting of ultrasonic wave and travels in the } \\
\text { propellant itself and reflected at the surface of the } \\
\text { propellant then return back to the transducer. }\end{array}$ & {$[12]$} \\
\hline 1962 & D.L. Johnson & Microwave technique & $\begin{array}{l}\text { Continuous measure for the shift of the phase in the } \\
\text { reflected signal from the propellant burning surface. }\end{array}$ & {$[13]$} \\
\hline 1963 & J. R. Osborn & High speed camera & $\begin{array}{l}\text { Recording the burning process of the material } \\
\text { and the rate of burning usually obtained by } \\
\text { the determination of the burned thickness } \\
\text { through the selected time interval. }\end{array}$ & {$[14]$} \\
\hline 1977 & L.H. Caveny & Acoustic Emission & $\begin{array}{l}\text { Timing the period of acoustic wave emission } \\
\text { during burning of propellant strip underwater. }\end{array}$ & {$[15]$} \\
\hline
\end{tabular}

\section{Experimental}

\section{II.1 Formulation and raw materials}

Aluminized Propellant composition has $86 \%$ solid fillers and $14 \%$ binder with 0.9 curing ratio( $\mathrm{NCO} / \mathrm{OH})$ were prepared by the cast technique. The propellant composition contains 69\% Ammonium perchlorate (AP), $17 \%$ Aluminum and $14 \%$ polyurethane matrix. The formulation was prepared in a vertical mixer and cured for certain time in oven. AP was dried at $850 \mathrm{C}$ for 48 hours. The binder matrix contains hydroxyl terminated polybutadiene (HTPB), hexa-methylene diisocynate (HMDI), dioctyl adipate (DOA) and Tris-1- (2, Methyl Aziridinyl) Phosphine Oxide (MAPO). At first, the ingredients of the binder (HTPB-DOA-MAPO)have been premixed under stirring of $150 \mathrm{rpm}$ at $600 \mathrm{C}$ for $10 \mathrm{~min}$., accompanied by inserting the $\mathrm{Al}$ fuel under mixing for 15 min. Then addition of AP takes place under continuous stirring for another 15 min. lastly, HMDI (curing gent) has been added to the previous mixture at $400 \mathrm{C}$ and left under stirring for $15 \mathrm{~min}$ on vacuum for degassing. The freshly prepared slurry was casted into three standard 2-inch test motor and one mold for propellant bulk production. Finally curing process takes place at $500 \mathrm{C}$ for 6 days.

\section{II.2 Sample preparation}

The completely cured blocks of composite propellants must be without any cracks. The grain must be prepared using pneumatic grain cutter. Samples have to be placed in a pouring direction firstly cut $5 \mathrm{~mm}$ thickness of the block skin. The dimensions are required as follow: width $6 \mathrm{~mm}$, thickness $6 \mathrm{~mm}$ and length $120 \mathrm{~mm}$ (Figure 2).

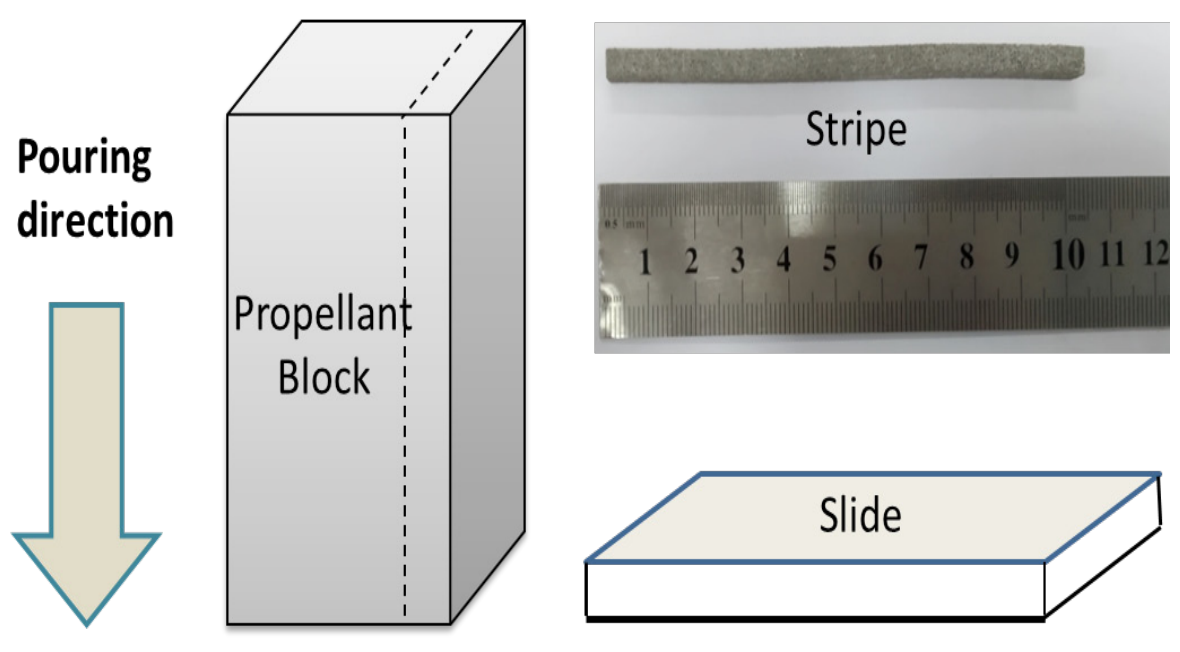

Fig. 2: Methodology of sample preparation. 


\section{II.3 Instrumentation}

The previously prepared composite solid propellant stripes were put into water-filled combustion chamber after fixing it in sample holder with the aid of (30 SWG) Ni-Cr wire as shown in Figure 4(b).

The combustion chamber is pressurized with different values of nitrogen from 5 to $9 \mathrm{MPa}$ and the operating temperature is adjusted by thermostat water channel as normal condition $\left(25^{\circ} \mathrm{C}\right)$. As soon as electrically started ignition process with (18 $\mathrm{V}$ and $2 \mathrm{Amp}$ current) takes place the burning starts from up to down and the acoustic wave starts to be emitted throughout the sample burning period $^{[16-19]}$.

The continuous acoustic emission signals, which created by specimen during burning, transferred through combustion chamber and received by sensor $(350 \mathrm{kHz}$ resonance acoustic transducer), have converted into electric signals, they are amplified by preamplifier and sent to data acquisitions system for calculation Figure 3. The time counter is stopped when the specimen burning is over. The burning rate at each certain pressure is calculated by the basic equation Eq. (1):

At which: is the specimen length of sample $(\mathrm{mm})$ and is calculated time of burning ( $\mathrm{s}$ ).

$$
r=\frac{\mathrm{L}}{\Delta \mathrm{t}}
$$

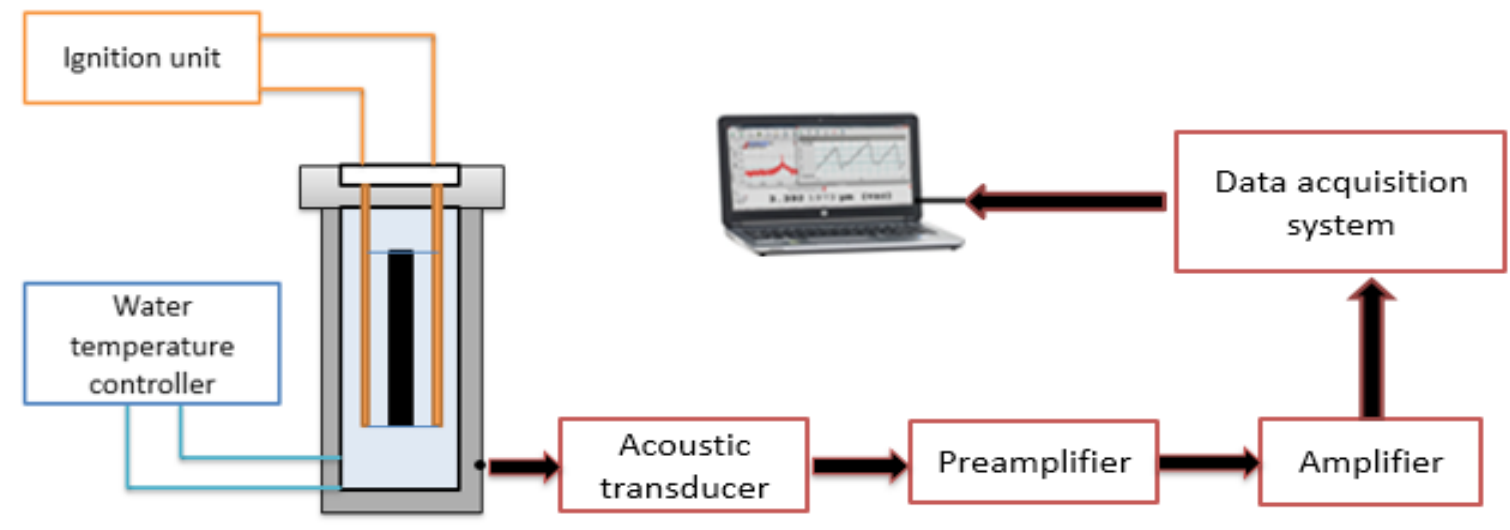

Fig. 3: Acoustic wave emission integrated system.

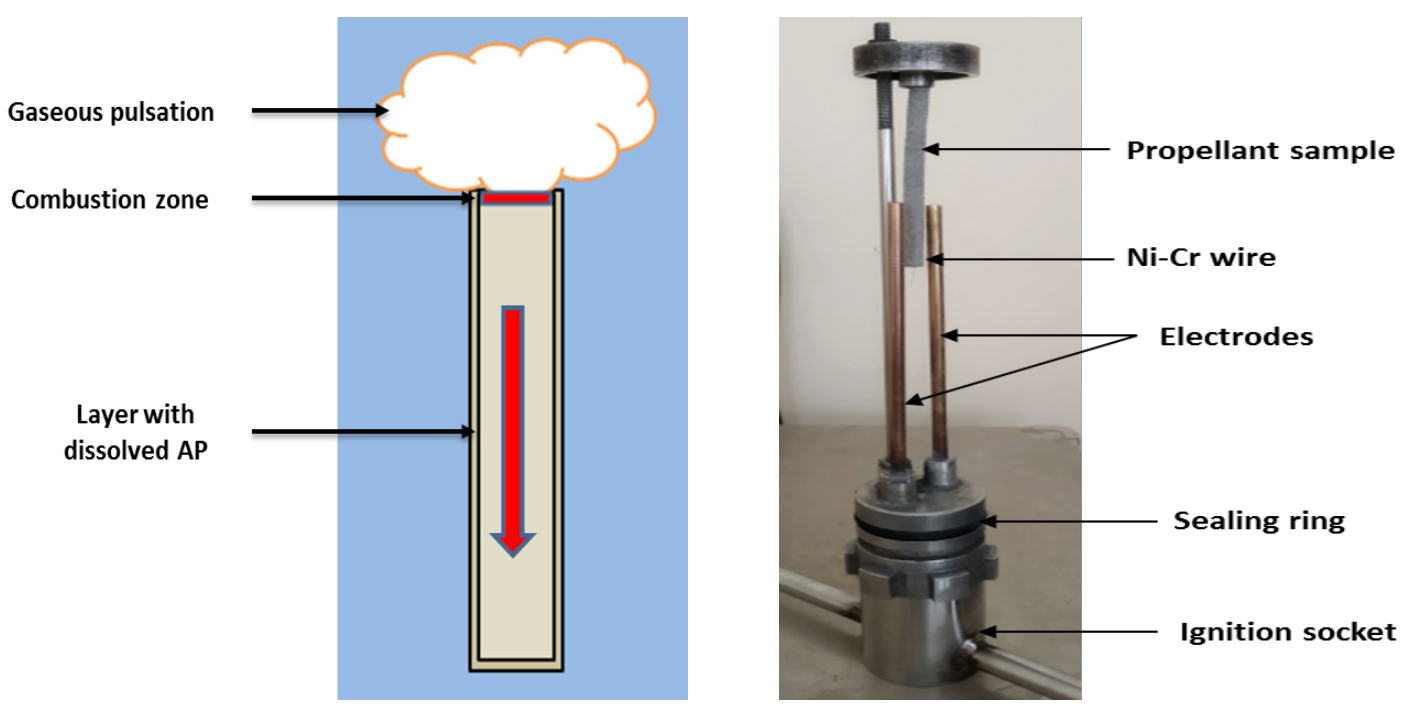

Fig. 4: (a) Pulsation prefigure and (b) Specimen fixation methodology. 
On the another hand, small scale test motors as shown in Figure 5 were prepared with different throat diameters as $7,7.3,7.6 \mathrm{~mm}$ respectively achieving different operating pressures and as a result different burning rates ${ }^{[17-20]}$.

The tested rocket motors were put onto function using igniter at $25^{\circ} \mathrm{C}$. The operating pressures were measured via special pressure transduces with two channels converting the pressure into electric signals which processed by special data acquisition system and the ballistic parameters were successfully plotted on the pressure-time curve Figure 6.

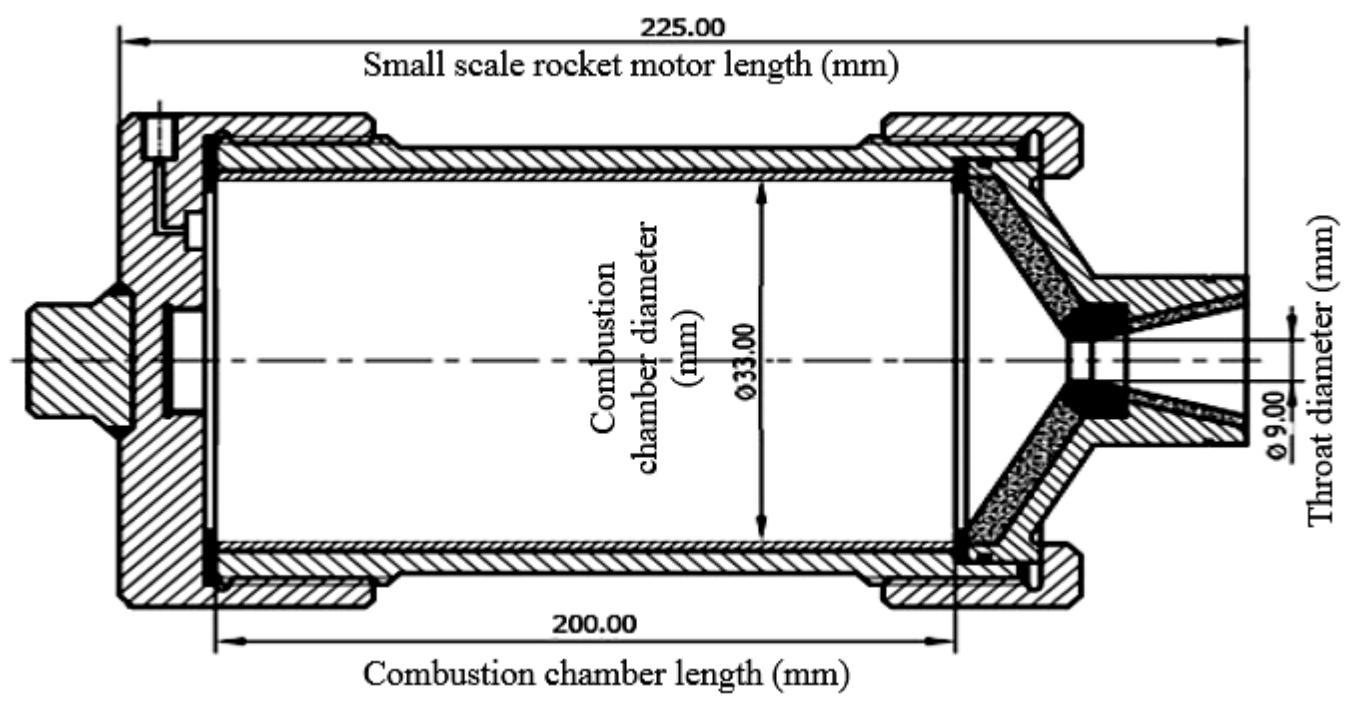

Fig. 5: Schematic for small scale test motor
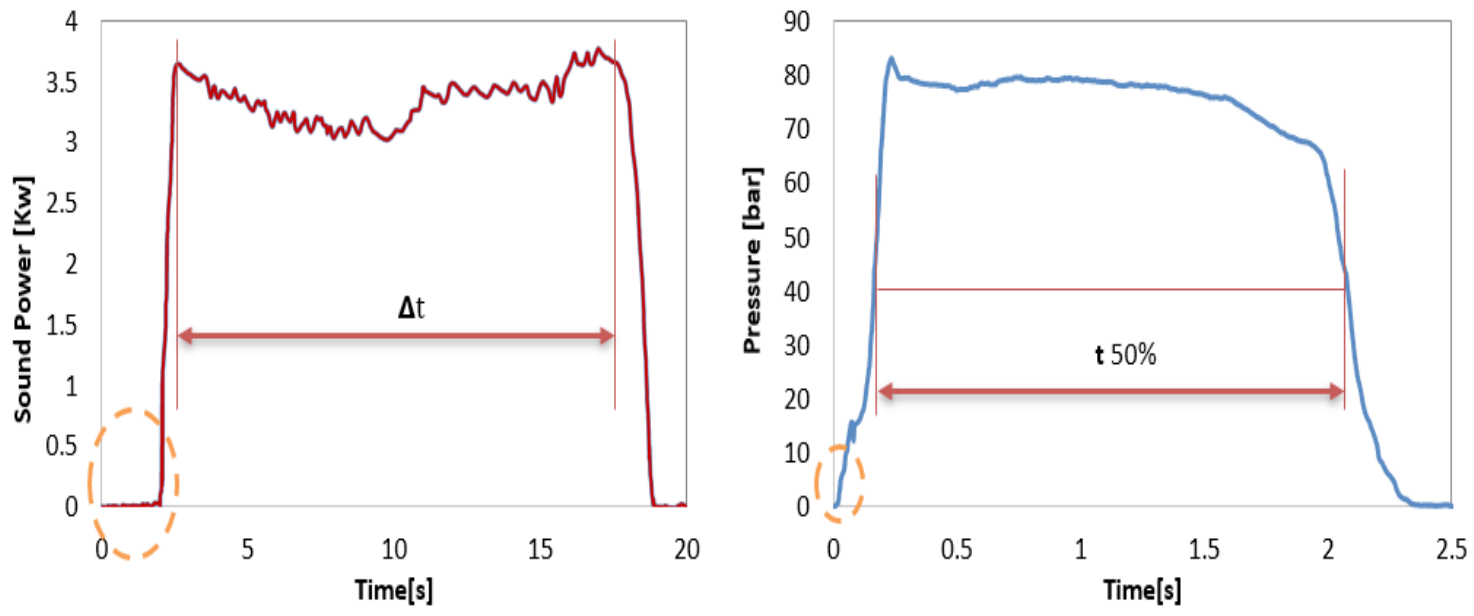

Fig. 6: Sound power-time and pressure-time curves.

\section{RESULTS AND DISCUSSION}

The combustion parameters could be calculated in accordance with burning rates measured under different pressures for both strand burner and 2-inch test motors as shown in Table. 2 by applying the burning rate eq. represented by Eq 2 .

$$
r=a P^{n}
$$

Here: is rate of burning $(\mathrm{mm} / \mathrm{s})$, is constant of burning rate, is the pressure exponent and is the operating pressure (MPa). 
Table 2: Comparative data obtained from strand burner and ballistic test motor.

\begin{tabular}{|c|c|c|c|c|c|c|c|c|c|c|c|c|c|c|c|}
\hline & \multicolumn{5}{|c|}{ WAE strand burner } & \multicolumn{5}{|c|}{ 2-inch ballistic test motor } & \multicolumn{5}{|c|}{ Crawford strand burner ${ }^{[13]}$} \\
\hline & $\mathrm{p}$ & $\mathrm{R}$ & a & $\mathrm{n}$ & $\mathrm{R} 2$ & $\mathrm{P} 50 \%$ & $\mathrm{R} 50 \%$ & a & $\mathrm{n}$ & $\mathrm{R} 2$ & $\mathrm{p}$ & $\mathrm{R}$ & $\mathrm{a}$ & $\mathrm{n}$ & $\mathrm{R} 2$ \\
\hline & $\mathrm{MPa}$ & $\mathrm{mm} / \mathrm{s}$ & & & & $\mathrm{MPa}$ & $\mathrm{mm} / \mathrm{s}$ & & & & $\mathrm{MPa}$ & $\mathrm{mm} / \mathrm{s}$ & & & \\
\hline 1 & 5 & 6.57 & & & & 6.70 & 7.28 & & & & 2 & 6.5 & & & \\
\hline 2 & 6 & 6.89 & & & & 7.92 & 7.60 & 2.7 & 0.23 & 0.99 & 4 & 6.89 & & & \\
\hline 3 & 7 & 7.18 & 2.69 & 0.22 & 0.98 & 8.54 & 7.70 & & & & 6 & 7.5 & 1.17 & 0.37 & 0.99 \\
\hline 4 & 8 & 7.38 & & & & & & & & & 8 & 8.4 & & & \\
\hline 5 & 9 & 7.50 & & & & & & & & & & & & & \\
\hline
\end{tabular}

The burning rate of Crawford Strand burner was obtained by measuring the burning distance between the two lead wires as well as the burning time of such distance. Four values of burning rate were calculated ${ }^{[13]}$.

Values of $\mathrm{P} 50 \%$ and $\mathrm{R} 50 \%$ are chosen as expressed data to avoid the instability of burning at pressure built up and tail off regions ${ }^{[20-23]}$.

Acoustic emission strand burner has higher delay of ignition time as chemical igniter in case of 2-inch motor is more powerful than electrical one as shown in Fig .6.This is because the typical products of the chemical igniter are high pressure gaseous products which accelerate the time required for sustainable burning stage and also glowing particles which improve the heat transfer to the first propellant surface layer reducing delay of ignition time.

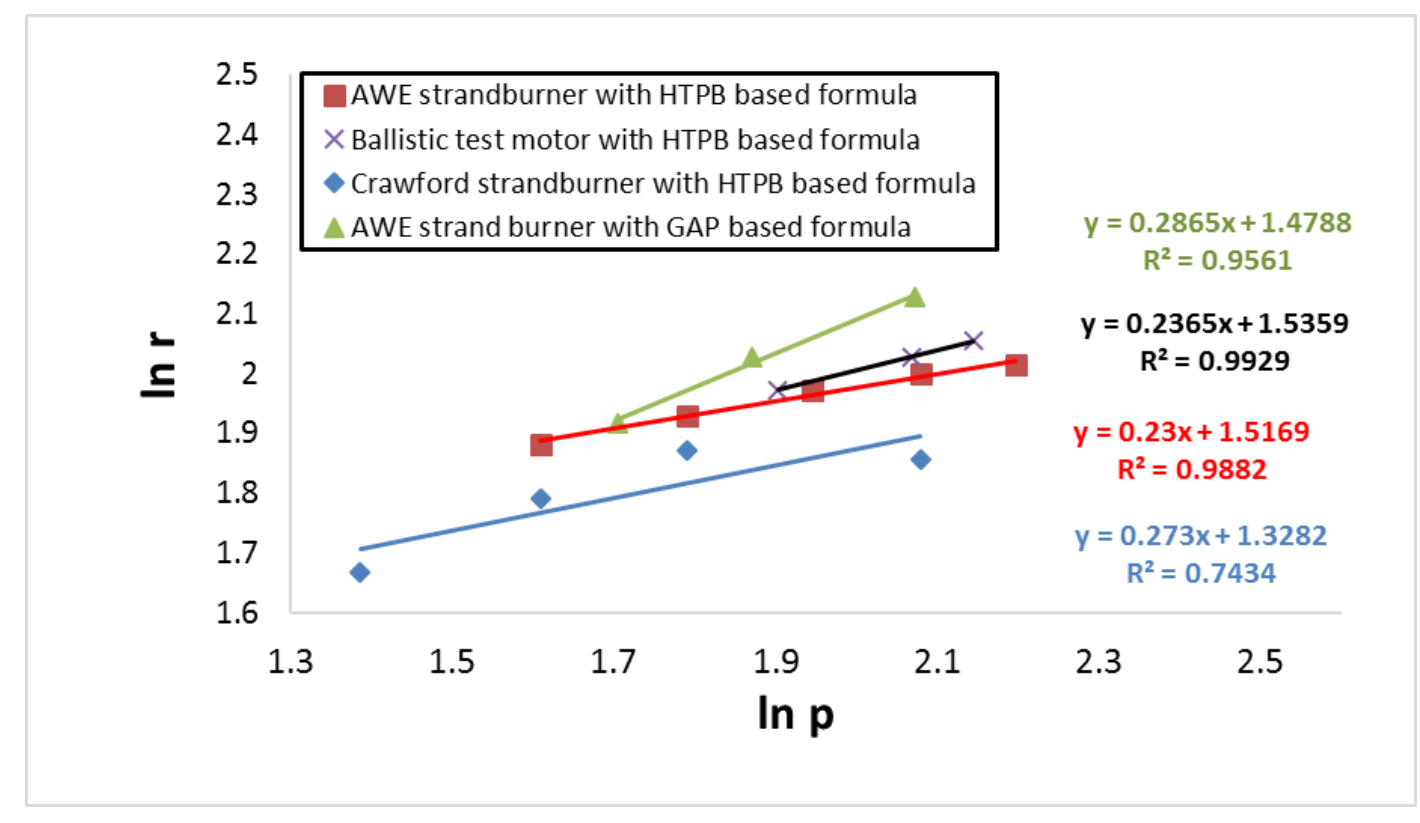

Fig. 7: comparative analysis of data obtained from both techniques.

Acoustic emission strand burner starts burning with sharp peak as it operates with already highly applied pressure unlike 2-inch motor burning which needs to operate exceeding built-up pressure value.

In case of acoustic emission strand burner after $10 \mathrm{sec}$, the curve gradually rises up which means increasing of burning rate as a result of pressure accumulation (confined system) so it isn't recommended to increase the specimen dimension than previously mentioned. Burning of propellant could be extinguished by water so under water burning stability principle should be achieved by applying gaseous pulsation as shown in Figure 4(a), which means 
that combustion layer is always protected from water by continuously generated gaseous bubble to overcome water tendency to fall down as a result of action of the gravity ${ }^{[24,25]}$.

In acoustic emission strand burner technique, water plays dual functions it used to inhibit the propellant specimen by dissolving AP presented on the outer surface creating low burning rate thin layer of inert binder matrix and also it used to enhance transferring of acoustic wave from burning surface to the acoustic wave sensor ${ }^{[26,27]}$.

The value of $3 \%$ as strand burner deviation co-efficient has been evaluated by calculation of burning rates with strand burner and 2-inch motor at $6.894 \mathrm{MPa}(1000 \mathrm{PSI})$ which founded to be 7.08 and $7.31 \mathrm{~mm} / \mathrm{s}$ respectively. The acoustic wave emission strand burner for formulation based on $\mathrm{GAP}^{[23]}$ demonstrates high burning rate and high sensitivity to pressure by comparing with formulation based on HTPB. This could be investigated to the fact that GAPis more powerful energetic binder in comparison to $\mathrm{HTPB}^{[28-30]}$. This also ascertain the validity of acoustic wave emission technique for different composite formulations with several operating parameters and wide range of applications $^{[22]}$.

\section{CONCLUSION}

The acoustic emission strand burner technique has many advantages over the conventional strand burners, unlike Crawford technique, acoustic emission technique requires no inhibitor no complex wiring and unlike smallscale test motor the acoustic emission technique requires small specimen to provide expressed ballistic data.

$3 \%$ as acoustic emission technique deviation coefficient was successfully investigated by comparing the burning rate of this technique and small-scale test motor at standard operating pressure $6.894 \mathrm{MPa}(1000 \mathrm{PSI})$. Small deviation in pressure exponent has dramatic effect on burning rate of propellant. The higher burning rate of 2-inch motor was investigated as a result of the erosive burning.

The acoustic emission strand burner could be useful for safe estimation of burning rate of aged propellant of largescale rocket motor with taking into account the estimated accuracy of this technique with the applied formulation.

\section{REFERENCES}

[1] Aziz A , Mamat R , Ali W K. Development of strand burner for solid propellant burning rate studies .IOP Conference Series: Materials Science and Engineering, 2013, 50, article id 012048 .

[2] Tawfik S, Saleh A, Elbeih A and Klapotke T, Reactive nanocomposites as versatile additives for composite propellants. Zeitschrift für anorganische und allgemeine Chemie, 2016, 642(21):1222-1229.

[3] Ghosh K, Behera S, Kumar A. Studies on Aluminized, High Burning Rate , Butacene ${ }^{\circledR}$ Based, Composite Propellants.Central European Journal of Energetic Materials , 2014, 11: 323-333.

[4] Kshirsagar D R, Jain S, Bhandarkar S.Studies on the Effect of Nano$\mathrm{MnO} 2$ in HTPB-based Composite Propellant Formulations.Central European Journal of Energetic Materials , 2017 , 14 :589-604.

[5] R. Bogusz, P. Magnuszewska, B. Florczak, A. Maranda, and K.
Droz ${ }^{\prime} z^{\prime}$ ewska, "Studies of the influence of nano iron(III) oxide on selected properties of solid heterogeneous propellants based on HTPB," Cent. Eur. J. Energ. Mater., vol. 13, no. 4, pp. 1051-1063, 2016.

[6] G. M. Gore, K. R. Tipare, R. G. Bhatewara, U. S. Prasad, M. Gupta and S. R. Mane, "Evaluation of Ferrocene Derivatives as Burn Rate Modifiers in AP / HTPB-Based Composite Propellants," vol. 49, no. 2, pp. 151-158, 1999 .

[7] M. Kohga and S. Togo, "Influence of iron oxide on thermal decomposition behavior and burning characteristics of ammonium nitrate/ammonium perchlorate-based composite propellants," Combust. Flame, vol. 192, pp. 10-24, 2018

[8] S. Isert, L. J. Groven, R. P. Lucht, and S. F. Son, "The effect of encapsulated nanosized catalysts on the combustion of composite solid propellants," Combust. Flame, vol. 162, no. 5, pp. 1821-1828, 2015.

[9] E. Elsaka and M. E. Awad, "Assessment of antioxidant resistance to thermal- oxidative degradation of stabilized polybutadiene binder," Int. Conf. Chem. Environ. Eng., pp. 1016-ICEE, 2020.

[10] A. Aziz, R. Mamat, and W. K. W. Ali, "Development of strand burner for solid propellant burning rate studies," vol. 16, no. 3, , 2013, pp. $182-190$.

[11] Isert S, Hedman T D, Lucht R P,Son S. F. Oxidizer coarse-tofine ratio effect on microscale flame structure in a bimodal composite propellant. Combust. Flame, 2016, 163: 406-413.

[12] Abd-Elghany M, Klapötke T M, Elbeih A and Zeman S. Investigation of different thermal analysis techniques to determine the decomposition kinetics of $\varepsilon-2,4,6,8,10,12$-hexanitro-2,4,6,8,10,12-hexaazaisowurtzitane with reduced sensitivity and its cured PBX. J. Anal. Appl. Pyrolysis, 2017, 26: 267-274

[13] Manship T D, Heister S D, Neil P T. Experimental Investigation of High-Burning-Rate Composite Solid Propellants. Propuls. Power, 2012, 28:145-153.

[14] Song SJ, Kim HJ, Kim IC, Yoo JC, Jung JY. Measurement of Solid Propellant Burning Rates by Analysis of Ultrasonic Full Waveforms, J. Mech. Sci. Technol., 2009, 23: 1112-1117.

[15] Vilyunov VN, Dvryashin AA. An Experimental Investigation of the Erosive Burning Effect.Combust. Explo. Shock Waves (Engl. Transl.), 1971, 7: 38-42.

[16] Keiichi H, Katsuya H, Shigeru S, Masataka S. Modified Ultrasonic Method for the Study of Burning Rate Characteristics for Propellants, 31st Int. Annu. Conf. ICT, 2000, 32: 1-12.

[17] Crawford B.L., Hugget C., Daniels F., Wilfong R.E., Direct Determination of Burning Rates of Propellant Powders, Anal. Chem., 1947, 19: 630-633.

[18] Deepak D, Jeenu R, Sridharan P,Padmanabhan M S. Application of ultrasonic technique for measurement of instantaneous burn rate of solid propellants. Def. Sci. J. , 1998 ,148: 197-204.

[19] Bozic VS, BlagojevicDD, Anicin BA. Measurement System for Determining Solid Rocket Propellant Burning Rate using Transmission Microwave Interferometry, J. Propul. Power, 1997, 13: 457-462.

[20] Osborn J R, Murphy J M,Kershner S D. Photographic measurement of burning rates in solid propellant rocket motors. Rev. Sci. Instrum., 1963, 34: 305-306.

[21] Lui F. A New Method for Measurement of Burning Rate of Propellant and Explosives. Combustion and Detonation Phenomena, 19th Int. Annu. Conf. ICT, 1988, 49:1-11.

[22] I. K. Boshra, A. Elbeih, L. Guo, and M. G. Zaki, "Composite Solid Rocket Propellant Based on GAP Polyurethane Matrix with Different Binder Contents," Huozhayao Xuebao/Chinese J. Explos. Propellants, vol. 43, no. 4, 2020, pp. 362-367.

[23] K. Menke, S. Eisele, M. Bohn, and P. Gerber, "Minimum Smoke Propellants with High Burning Rates and Thermodynamic Performance," Rto-Mp-091, no. 13, pp. 1-20, 2002.

[24] I. K. Boshra, A. Elbeih, and H. E. Mostafa, "Composite solid rocket propellant based on GAP polyurethane matrix with different plasticizers," IOP Conf. Ser. Mater. Sci. Eng., vol. 610, no. 1, 2019.

[25] G. Gupta, L. Jawale, Mehilal, and B. Bhattacharya, "Various methods for the determination of the burning rates of solid propellants an overview," Cent. Eur. J. Energ. Mater., 2015.

[26] S. K. Lalith V. Kakumanu, Narendra Yadav and T, "Combustion Study of Composite Solid Propellants Containing Metal Phthalocyanines," Int. J. Aerosp. Sci., vol. 3, no. 2, 2014, pp. 31-36.

[27] Caveny LH, Saber AJ, Summerfield M. Propellant Burning Rate Uniformity Identified by Ultrasonic Acoustic Emissions. Journal of Spacecraft and Rockets, 1977, 14: 434-437. 
[28] Miller WH, Barrington DK. A Review of Contemporary Solid Rocket Motor Performance Prediction Techniques. Journal of Spacecraft and Rockets, 1970, 7: 225-237.

[29] Bossi I, Ferriello P, Deluca LT. Acoustic emission of under water burning composite solid rocket propellants. AIDAA conference, 2017.
[30] I. K. Boshra, A. Elbeih, and H. E. Mostafa, "Improving the Mechanical Properties of Glycidyl Azide Polymeric Matrix Used in Composite Solid Rocket Propellant by Adding Advanced Cross-Linker," Zeitschrift fur Anorg. und Allg. Chemie, vol. 645 , no. 5 , 2019, pp. 551-557. 